\title{
Foraging site displacement in common crane flocks
}

\author{
LUIS M. BAUTISTA*, JUAN CARLOS ALONSO* \& JAVIER A. ALONSO† \\ *Departamento de Ecología Evolutiva, Museo Nacional de Ciencias Naturales, Madrid \\ $\dagger$ Departamento de Biología Animal, Facultad de Biología, Universidad Complutense
}

(Received 15 December 1997; initial acceptance 27 January 1998;

final acceptance 23 April 1998; MS. number: 5729R)

\begin{abstract}
Optimal foraging theory predicts that an individual should resort to intraspecific kleptoparasitism when this foraging strategy helps to maximize its intake rate. Thus aggressor and victim should be foraging at lower and higher rates, respectively, than the flock average (intake rate maximization). Independent of the maximization principle, moreover, an aggressor should attack when its intake rate falls below a threshold critical for survival, and select a victim foraging at an intake rate high enough to ensure survival (starvation risk minimization). We tested both hypotheses using 324 aggressive displacements from feeding sites observed in flocks of common cranes, Grus grus, foraging on cereal fields. Aggressors attacked cranes feeding at higher rates than average birds. The immediate consequences of a successful attack were an increase in intake rate for the aggressor and a decrease for the victim. The intake rate of the aggressor prior to the attack was lower than both the mean intake rate of the flock and the minimum intake rate necessary to cover basic metabolic needs. After displacing its victim, the intake rate of the aggressor was higher than before the attack and also higher than the average intake rate of the flock. The intake rate of the aggressor after the attack was not higher than the mean intake rate of the flock, however, when the time spent on the attack was included. We conclude that cranes used a kleptoparasitic strategy to recover from temporary reductions in feeding rate. This was particularly the case below the threshold of intake necessary for survival.
\end{abstract}

(C) 1998 The Association for the Study of Animal Behaviour

In flock-foraging species, individuals can benefit from the feeding success of their flock mates through kleptoparasitic behaviour such as food stealing, or displacing other individuals from good feeding sites. To provide the resource base on which the behaviour depends, individuals must search for food themselves, and not all individuals within a flock can resort to stealing food. Thus, either a few individuals kleptoparasitize frequently, or many individuals do it infrequently (Brockmann \& Barnard 1979; Barnard \& Sibly 1981; Barnard 1984; Vickery et al. 1991). Some field studies have shown that kleptoparasitism is unevenly distributed in a population, probably because the value of food stealing is not the same for all individuals. For example, the profitability of this behaviour may be inversely related to the hunting proficiency of the individual, which is often associated with age (Burger \& Gochfeld 1981; Gochfeld \& Burger 1981; Furness 1987). While some studies, however, have found that juveniles rob more frequently than adults because

Correspondence: L. M. Bautista, Departamento de Ecología Evolutiva, Museo Nacional de Ciencias Naturales, José Gutierrez Abascal 2, 28006 Madrid, Spain (email: Imbautista@mncn.csic.es). J. A. Alonso is at the Departamento de Biología Animal, Facultad de Biología, Universidad Complutense, 28040 Madrid, Spain.

0003-3472/98/111237+07\$30.00/0

they are less skilful at finding food themselves, other studies show opposite results (Brockmann \& Barnard 1979; see references in Wunderle 1991, page 294; Steele \& Hockey 1995). Finally, adults may be more efficient kleptoparasites (Burger \& Gochfeld 1981; Hockey \& Steele 1990), and a high dominance rank may reduce the time necessary to steal food from other individuals (Caraco et al. 1989).

To know whether kleptoparasitism can be considered an alternative feeding strategy in a population, quantitative data comparing the costs and benefits of this behaviour with respect to other feeding strategies are needed. Data on the efficiency of this behaviour are also contradictory, however. Some studies have suggested that kleptoparasitism is a less efficient feeding technique than hunting (Kushlan 1978, 1979; LeBaron \& Heppner 1985; Furness 1987), while others have found that it is profitable in some species (Dunbrack 1979; Ens et al. 1990). In this paper we quantify some costs and benefits of aggressive displacements among common cranes, Grus grus, foraging gregariously on cereal fields in winter. Studies on food stealing have mostly been carried out with species feeding on large, visible food items (Brockmann \& Barnard 1979; Goss-Custard et al. 1982, 1984; Ens \& 
Goss-Custard 1984). Although site displacement has been recorded in several bird species (Vines 1980; Metcalfe 1986; Amat \& Obeso 1991), the difficulties in quantifying food intake rates have frequently prevented a detailed study of this behaviour (although see Caldwell 1980; Rohwer \& Ewald 1981; Greig et al. 1985). Because the cranes' diet was almost exclusively cereal seeds, however, we were able to quantify intake rate in this study relatively easily.

We studied foraging site displacement in the context of current foraging theory (Stephens \& Krebs 1986), predicted the food intake rate of both the aggressor and the victim prior to a site displacement, and observed the benefits or costs in terms of food intake rate after the attack. According to optimal foraging theory, a forager will resort to food stealing or site displacement when the net energy gain derived from this behaviour exceeds the net energy gained from searching for food itself (Charnov 1976). Furthermore, a food intake maximizer with perfect information should select as victims those flock mates foraging at the highest rates, because only by displacing those birds will it maximize its own intake rate.

If individuals were only following a simple intake maximization rule, there would probably be continuous food site displacements in a flock, since it is always possible to find flock mates feeding at higher rates. Attacking a flock mate also implies some costs to the aggressor, however, the most obvious one being the possibility of being injured by a victim defending itself. Among several factors determining success in aggressive encounters, the most important are probably body size and condition, and the previous possession of the disputed resource. Animal contest theory predicts that larger animals or those owning resources tend to obtain or maintain them when confronted with a conspecific (review in Maynard Smith 1982; Huntingford \& Turner 1987). In previous studies we indeed found that larger adult cranes were usually dominant in aggressive encounters, displacing subdominant birds from good feeding positions (Bautista et al. 1995), although they were not involved in more atacks than other birds (Alonso et al. 1997). So, could there be a simple rule for any aggressor, independently of its competitive ability and optimal foraging theory, to decide when to attack another bird? Several studies have shown that kleptoparasitism is enhanced when food is less abundant, because in such situations the relative value of the food discovered increases (Lockie 1956; Recher \& Recher 1969; GossCustard 1970; Brockmann \& Barnard 1979; Birt \& Cairns 1987; Enquist \& Leimar 1987; Amat 1990). An individual risks starvation if it keeps foraging at a low intake rate for a long time. Also, hungry individuals usually initiate an attack and take control over the food (e.g. Cristol 1992). These studies suggest that the internal state of an individual can play an important role in deciding whether to attack, independently of any intake rate maximization rule.

Thus our first predictions were a victim should forage at a higher rate than both (1) the aggressor and (2) average flock mates (intake rate maximization). We also predicted (3) that the intake rate of the aggressor before attacking should be lower than the average intake rate of the flock. Predictions 2 and 3 are context sensitive, because they are expressed relative to the mean intake rate of the flock. Independent of the maximization principle, we also predicted that before the attack (4) the aggressor should be foraging at a rate below the survival risk threshold, whereas (5) the victim's intake rate should be equal to or higher than that threshold (starvation risk minimization). Predictions 4 and 5 are independent of the mean intake rate of the flock. We used the survival risk threshold calculated during a previous study (Alonso et al. 1995) as the minimum acceptable food intake rate to meet basic daily metabolic needs.

\section{METHODS}

Between December and late February 1989-1990 and 1990-1991 we studied the foraging behaviour of common cranes at Laguna de Gallocanta, an over 80 000-ha cereal farmland in northeastern Spain that is regularly used by the species as a staging and wintering area (Bautista et al. 1992). Minimum numbers of cranes were 3338 and 6828 , respectively, during the first and second winters (Alonso $\&$ Alonso 1996). A more detailed description of the study area and its use by the cranes is given in Alonso et al. (1994) and Bautista et al. (1995). Canes disperse daily from a communal roost in the lake to forage in flocks on the surrounding fields, the majority of which are sown with winter wheat and barley. We located foraging flocks continuously throughout the day and observed birds with $\times 60-90$ Questar telescopes from distances of 500$1000 \mathrm{~m}$ to avoid disturbing them. In each flock we taperecorded the behaviour of 7-10 randomly selected adult birds for $1 \mathrm{~min}$ each. The time devoted to different activities was measured to the nearest $1 \mathrm{~s}$. We measured the rate of food intake by counting the number of swallowing movements of the birds. During winter, the cranes fed almost exclusively on cereal seeds buried $2-3 \mathrm{~cm}$ below ground. When searching for sown cereal, cranes walk slowly across a field making sideward movements to remove the surface earth and dig up the seeds. When they find a seed they take it and make a characteristic backward movement of their long neck which is very apparent to the observer. Since this foraging technique forces the birds to take the seeds one by one, the number of swallowing movements is equal to the number of seeds ingested, according to our observations of free-living and captive cranes. We defined instantaneous food intake rate as the intake rate while head down, actively feeding. We calculated the mean instantaneous intake rate of each flock by averaging the values of the 7-10 flock members observed. We used this mean instantaneous intake rate as an estimate of the patch quality (see Alonso et al. 1995) when controlling for the effect of patch quality on intake rate gain. We assumed that a crane risked starvation if its instantaneous food intake rate was below $0.31 \mathrm{~g}$ of cereal per min (0.156 seeds per $s$ ), because if foraging permanently below this rate it would not meet its basic daily metabolic needs (121 g per day, for details see Alonso et al. 1995). 
Table 1. Time spent foraging actively (i.e. with the head down), instantaneous intake rate and pacing rate of cranes on cereal-sown fields before and after a foraging site displacement

\begin{tabular}{|c|c|c|c|c|}
\hline & \multicolumn{2}{|c|}{ Time before the attack } & \multicolumn{2}{|c|}{ Time after the attack } \\
\hline & Up to $60 \mathrm{~s}$ & $10 \mathrm{~s}$ & $10 \mathrm{~s}$ & Up to $60 \mathrm{~s}$ \\
\hline \multicolumn{5}{|c|}{ Time foraging (\%). Flock mean: $91 \pm 1$ (251) } \\
\hline Aggressor & $88 \pm 2(118)$ & $79 \pm 3(118)^{\star \star}$ & $85 \pm 3(113)$ & $87 \pm 2(114)$ \\
\hline Attacked & $96 \pm 1(132)^{* *}$ & $92 \pm 2(130)$ & $67 \pm 3(125)^{* *}$ & $80 \pm 3(128)^{* *}$ \\
\hline \multicolumn{5}{|c|}{ Instantaneous intake rate (seeds per min). Flock mean: $10 \pm 1(251)$} \\
\hline Aggressor & $8 \pm 1(118)^{* *}$ & $6 \pm 1(118)^{\star *}$ & $12 \pm 1(113)^{*}$ & $11 \pm 1(114)$ \\
\hline Attacked & $10 \pm 1(132)$ & $12 \pm 1(130)^{*}$ & $4 \pm 1(124)^{\star *}$ & $6 \pm 1(128)^{\star *}$ \\
\hline \multicolumn{5}{|c|}{ Movement rate (paces per min). Flock mean: $9 \pm 1$ (251) } \\
\hline Aggressor & $16 \pm 2(118)^{\star *}$ & $19 \pm 2(118)^{\star *}$ & $12 \pm 1(114)$ & $11 \pm 1(114)$ \\
\hline Attacked & $7 \pm 1(132)^{*}$ & $8 \pm 1(130)$ & $23 \pm 2(124)^{* *}$ & $20 \pm 12(128)^{\star *}$ \\
\hline
\end{tabular}

Mean values $( \pm S E)$ of the flock, the aggressors and the attacked birds are given. Sample sizes (number of individuals) are given in parentheses. Values significantly different from the mean value of the flock are indicated with an asterisk $\left({ }^{*} P<0.05 ;{ }^{*} P<0.001\right.$, Student's $t$ test).

Aggressive encounters between cranes feeding gregariously on cereal-sown fields were usually attacks to displace another bird from a good feeding site. These encounters usually involved a short period of threat or a quick attack, with the victim usually fleeing almost immediately, although it sometimes defended itself. The aggressor usually took up the feeding site previously occupied by the victim. Since seeds are sown in parallel lines, once a seed or patch of seeds is discovered, the probability of finding further seeds in the immediate vicinity is relatively high. We measured the duration of an attack from the moment the aggressor initiated the attack until it resumed active foraging. For analysis each aggressive interaction (and the behaviour during the corresponding observation minute) was considered as an independent datum. The risk of pseudoreplication is negligible given the high number of birds in the study area (almost 10 000), and the comparatively few attacks recorded (416).

We pooled data from both years for analysis because differences between years in the behavioural variables studied were not significant (Alonso et al. 1997), and the patterns of general crane and food distribution in the study area were also similar between years (Bautista et al. 1995). All statistical tests were two-tailed.

During the study we captured 50 cranes with oral tranquillizers and rocket nets and fitted 35 of them with radiotransmitters. We used $\alpha$-chloralose to capture the birds, mixing it with cereal seeds. We observed no apparent long-term effect on the behaviour of the birds once they had recovered (1-4 h after capture, see Bishop 1991). The radiotransmitter weighed $70 \mathrm{~g}(<2 \%$ of the mean body mass of a crane during winter). We estimated the dominance rank of 12 of the cranes as the percentage of aggressive encounters with any other flock members, whether marked or not, that the focal animal won. We refer to dominant cranes as those winning more than $50 \%$ of aggressive encounters, and subordinates those winning less. The sample size of radiomarked cranes was later reduced to 10 birds because we did not record kleptoparasitic behaviour for two of them. Data on dominance rank for these birds and details of the behaviour of marked individuals are given in Bautista et al. (1995) and Alonso et al. (1997).

\section{RESULTS}

We observed feeding site displacements in 416 (5.1\%) of 8150 observations of foraging cranes of $1 \mathrm{~min}$ each. Thus, an average bird was involved in 5.1 encounters per $100 \mathrm{~min}$. The majority of attacks $(N=324,78 \%$ of the total) occurred on cereal-sown fields, the most frequently used foraging substrate during winter in the study area (Alonso et al. 1984, 1994). The majority of the attacks $(83 \%)$ were not repelled by the victim.

\section{Time Foraging Before and After an Attack}

Prior to an attack, the victim spent more time actively feeding than its flock mates, while the aggressor spent significantly less time actively feeding and more time scanning (Table 1; scanning time $=100$ - time actively feeding), probably to select an appropriate victim. After the attack, the victim resumed foraging almost immediately, but it spent significantly less time head down than other flock mates during the 1 min after the attack.

\section{Duration of an Attack}

Nonrepelled attacks lasted $3.5 \pm 0.1 \mathrm{~s}(\bar{X} \pm \mathrm{SE}, N=259)$, significantly less than repelled attacks $(4.3 \pm 0.4 \mathrm{~s}, N=53$; Student's $t$ test: $\left.t_{310}=-2.34, P=0.020\right)$. In nonrepelled attacks the victim spent more time in an alert posture after the attack than the aggressor did (mean difference $\left.0.8 \mathrm{~s} ; t_{257}=-2.88, P=0.004\right)$. In repelled attacks there was no difference in the duration of the aggression between birds $\left(t_{51}=0.52, P=0.604\right)$. Attacks were shorter than the average time needed to dig up a single seed $(\bar{X} \pm \mathrm{SE}=$ $\left.8.5 \pm 0.3 \mathrm{~s}, N=255 ; t_{254}=17.4, P<0.001\right)$. 


\section{Movement Before and After an Attack}

Prior to an attack, the aggressor was moving much more than its flock mates, while the victim was moving significantly less than other birds at least for the 1 min before the attack (Table 1). The situation reversed after the attack, with the victim moving many more paces than its flock mates and the aggressor moving at similar rates to other birds.

The number of paces moved during the attack by a crane that did not repel it was $3.1 \pm 0.2(\bar{X} \pm \mathrm{SE}, N=137)$, compared to only $0.9 \pm 0.1$ paces moved by the aggressor $\left(t_{257}=-9.93, P<0.001\right)$. However, the aggressor moved more when the attack was repelled $(\bar{X} \pm \mathrm{SE}=1.9 \pm 0.5$ paces, $N=29)$, and the victim moved less $(2.0 \pm 0.6$ paces, $N=24$ ), so that the differences between them disappeared $\left(t_{51}=-0.18, P=0.856\right)$.

\section{Food Intake Before and After an Attack}

Aggressors were successful in increasing their food intake rate during the $10 \mathrm{~s}$ after displacing another bird on $81 \%$ of attacks. This percentage decreased to $66 \%$ when we used the whole minute of observation. As for the victims, their intake rate during the $10 \mathrm{~s}$ after the attack decreased on $84 \%$ of occasions, or on $65 \%$ of occasions when we used the whole minute.

The intake rates of aggressor and victim during the $10 \mathrm{~s}$ before a nonrepelled attack were, respectively, lower and higher than the mean intake rate of other birds (Table 1). In the case of aggressors, the difference with respect to the flock extended over the whole minute of observation prior to the attack. During the $10 \mathrm{~s}$ after the attack, the differences with respect to the flock mean reversed: the aggressor foraged at higher, and the victim at lower, intake rates than the flock mean, the latter effect lasting over the whole minute of observation. However, if the aggression time was added to the $10 \mathrm{~s}$ after a nonrepelled attack, the intake rate of the aggressor for the resulting period decreased to $9.6 \pm 1.2$ seeds $/ \mathrm{min}(\bar{X} \pm \mathrm{SE})$ which was not different from the average intake rate for the flock $\left(t_{107}=0.58, P=0.562\right)$.

With respect to its own intake rate before the attack, a successful aggressor obtained a significant increase in intake (60-s period: $t_{110}=3.86, P<0.001$; Fig. 1 ), while the victim suffered a significant decrease of a similar magnitude (60-s period: $\left.t_{123}=3.22, P<0.002\right)$. In the rare case of a repelled attack, there was no significant change in intake rate for either aggressor $(\bar{X} \pm \mathrm{SE}=-0.01 \pm 0.03$ seeds $\left./ \mathrm{s} ; \quad t_{26}=-0.41, \quad P=0.686\right)$ or victim $(0.03 \pm 0.03$ seeds $/ \mathrm{s} ; t_{20}=-1.0, P=0.350 ;$ Fig. 1$)$. Thus, after a repelled attack victims continued feeding at a higher intake rate and aggressors at a lower intake rate than their flock mates.

\section{Intake Rate and Survival Risk Threshold}

The average intake rate of a victim before it was displaced was only marginally higher than the survival risk threshold $(\bar{X} \pm \mathrm{SE}=0.20 \pm 0.02$ seeds/s; one-sample $t$ test:

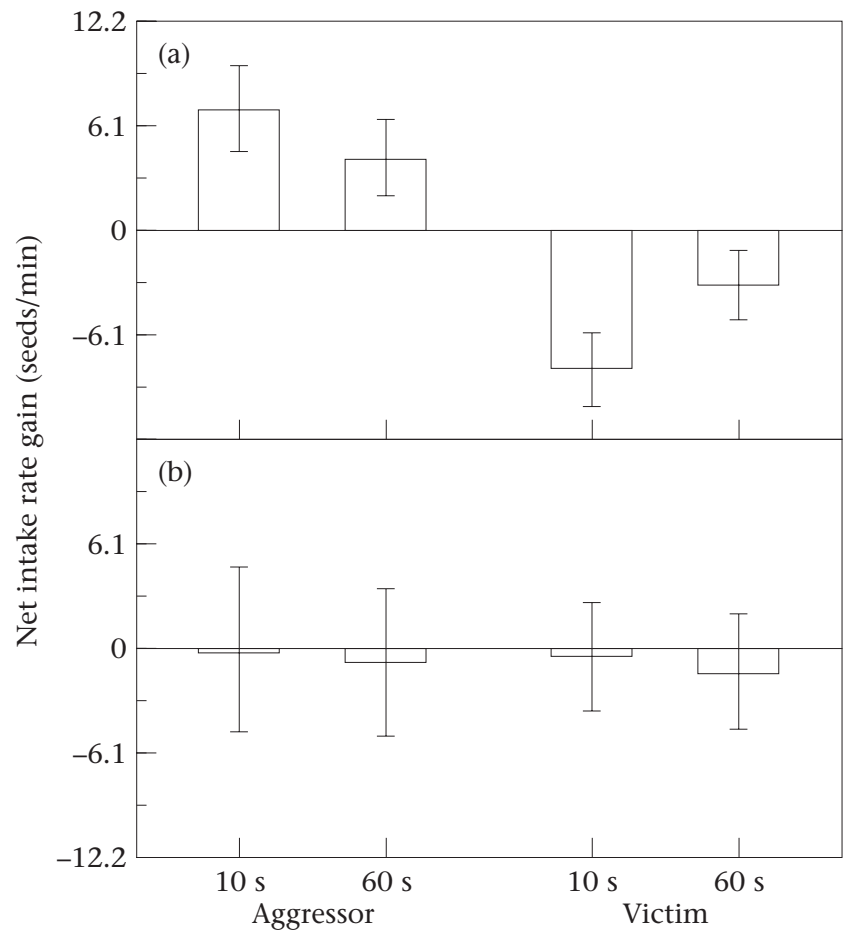

Figure 1. Mean instantaneous intake rate gain of cranes after a foraging site displacement in which the victim (a) did not repel the aggressor or (b) did repel the aggressor. Gain was calculated for 10-s and 60 -s periods before and after the attack. Vertical lines are the $95 \%$ confidence intervals.

$\left.t_{132}=1.67, P=0.097\right)$, but after the attack it was clearly below this threshold $\left(0.06 \pm 0.01\right.$ seeds $/ \mathrm{s} ; t_{123}=-9.94$, $P<0.001)$. The intake rate of an aggressor before the attack was below the survival risk threshold $(\bar{X} \pm \mathrm{SE}=0.09 \pm 0.02$ seeds/s; one-sample test: $\left.t_{118}=-5.65, P<0.001\right)$, but after the attack it was not different from this threshold $\left(0.21 \pm 0.02\right.$ seeds $\left./ \mathrm{s} ; t_{112}=1.35, P=0.180\right)$.

\section{Intake Rate Gain and Dominance Rank}

The intake gain of an aggressor after displacing a victim was only marginally correlated with the aggressor's dominance rank $\left(r_{\mathrm{S}}=0.59, N=10, P=0.078\right)$. A Fisher's exact test further indicated that the relationship between intake gain and dominance was not random: six cranes with an intake gain below the observed mean intake gain $(0.147$ seeds/s, $N=10$ birds) had a dominance rank below the observed mean dominance rank $(59.6 \%, N=10$ birds, $P=0.033)$. The loss in intake suffered by the victim as a consequence of being attacked was not correlated with its dominance $\operatorname{rank}\left(r_{\mathrm{S}}=-0.11, N=9, P=0.758\right)$.

\section{Relationship between Intake Rate and Attack Duration}

The time a crane is prepared to spend defending a foraging site should be correlated with the potential decrease in intake rate if it is displaced by an aggressor. Thus, attacks directed to birds with high intake rates 
should be expected to last longer. However, the duration of the attack was not correlated with either the aggressor's or victim's intake rate $(r=-0.12, N=119, P=0.21$ for aggressors; $r=0.03, N=133, P=0.72$ for victims), nor with the increase in intake after the attack $(r=0.01, N=110$, $P=0.91$ for aggressors; $r=0.04, N=123, P=0.7$ for victims), nor with the average intake rate of flock mates $(r=-0.03$, $N=120, P=0.74$ for aggressors; $r=0.04, N=135, P=0.69$ for victims). To control for the effect of patch quality on intake gain, we calculated the residuals of the linear regression of intake gain after an attack on the mean intake rate of the flock for aggressors $\left(F_{1,110}=3.85\right.$, $P=0.052)$ and victims $\left(F_{1,119}=4.47, P=0.037\right)$. The duration of an attack was not correlated with the residuals of intake gain for aggressors $(r=0.01, N=109, P=0.92)$ or victims $(r=0.03, N=121, P=0.78)$. We conclude that the duration of a nonrepelled attack was independent of the magnitude of change in food intake rate experienced by aggressors or victims as a consequence of the attack.

\section{DISCUSSION}

Feeding site displacements in crane flocks foraging on cereal fields were relatively infrequent. In spite of the marked gregariousness of the species in winter, which in principle would facilitate food stealing through group information mechanisms (Valone 1989), we observed this behaviour on only $5 \%$ of the observation samples, and a crane obtained through this strategy only a minor fraction (1-5\%) of its total daily food intake (a crane ingests between 3600 and 5400 cereal seeds, or 120-180 g/day, Alonso \& Alonso 1992; Bautista et al. 1995). Our results suggest that cranes resorted to this kleptoparasitic strategy wen they risked starvation. The mean intake rate of an aggressor prior to an attack was lower than the victim's intake rate (prediction 1 ), and the average intake rate of other flock mates (prediction 3) and clearly below the survival risk threshold estimated for wintering cranes in our study area (prediction 4; see Alonso et al. 1995). After the attack, the mean intake rate of the aggressor increased significantly and remained at a value not different from the survival rate. Displacing a flock mate from a good feeding site may therefore be interpreted as a way to retrieve the average food intake rate of other flock mates after a temporary failure in finding food and to recover a feeding rate at least equivalent to the survival threshold. In fact, displacing a flock mate was not more profitable for a crane than searching for food itself: the intake rate of an aggressor during the period including both the attack time and the $10 \mathrm{~s}$ after the attack was not different from the average intake rate of its flock mates. The rapid decrease of the higher intake rate gained by the aggressor after a displacement to average intake values of the flock suggests that increases of intake rate obtained by displacing victims from good feeding sites were only ephemeral. The relatively low profitability of aggressive displacements with respect to searching for food is probably the reason why this kleptoparasitic strategy is not more widespread in the population.

In spite of its rarity, displacing a flock mate from a good feeding site represented an obvious benefit to the aggres- sor. A successful aggressor increased its own intake rate, while the victim suffered a decrease similar in magnitude. Immediately before the attack, the instantaneous intake rate of the aggressor had clearly decreased below both the mean intake rate of the flock and the survival risk threshold, while the victim was foraging at a rate above the mean intake rate of other flock mates (prediction 2) although only marginally above the survival risk threshold (prediction 5). Intake rates of aggressor and victim were both different from the mean intake rate of the flock, which suggests that both rates probably played a role in the aggressor's decision to initiate a foraging site displacement. The decrease in intake rate of the aggressor was apparently the main factor releasing the attack, but before attacking, the aggressor had probably been monitoring the feeding success of its neighbours, as suggested by the higher percentage of time spent vigilant, and also by the greater number of paces moved. The fact that the intake rate of the victim was significantly higher than the average intake rate of the flock only during the $10 \mathrm{~s}$ before the attack (see Table 1) suggests that increases in intake rate are rapidly detected by potential aggressors. Thus, the aggressor might have based its decision to attack on its own intake rate compared to the survival rate threshold, and selected its victim by the latter's intake rate and, probably, size (as an indicator of its dominance status, see Bautista et al. 1995).

Foraging site displacements did appear in the behavioural repertoire of the majority of individuals radiotracked (see also Alonso et al. 1997), which suggests that it is a strategy used by probably all individuals in the population under the circumstances discussed above. There was no evidence that certain individuals specialized in displacing other flock mates as their main foraging strategy, but our results are in accordance with those of other studies (Ens \& Goss-Custard 1984; review in Wunderle 1991), where the amount gained by aggressive behaviour increased with dominance status. Although the percentage success of aggressive encounters was positively correlated with the size of the bird (Bautista et al. 1995), extremely dominant or subordinate cranes were involved in fewer attacks than their flock mates (Alonso et al. 1997). It is possible that top-dominant cranes displaced other birds not by attacking them, but simply by signalling their status while approaching them. These very subtle avoidance movements by subordinate flock mates might have passed unnoticed to a human observer. Given their higher success in aggressive encounters, large, dominant individuals could have been expected to specialize in stealing food (Brockmann \& Barnard 1979; Barnard 1984). However, since dominant cranes selected higher quality areas as their main foraging sites, and had higher mean food intake rates once the effect of patch quality differences was accounted for (Bautista et al. 1995; Alonso et al. 1997), they probably did not need to use feeding site displacements as a principal foraging strategy except on the relatively rare occasions when they failed to reach a critical minimum intake rate.

Several authors have found that kleptoparasitic behaviour is unevenly distributed in a population (Burger \& Gochfeld 1981; reviewed in Wunderle 1991). The 
general assumption is that this behaviour should be most important to birds that are inefficient foragers and hence may be more food stressed than efficient foragers (Furness 1987; Goss-Custard et al. 1998). In our case, inefficient cranes (i.e. juveniles) were not involved in more aggressive encounters than experienced, older birds (Alonso \& Alonso 1993) and juveniles were never observed to attack adults.

Finally, an unknown percentage of attacks might have been unrelated to foraging. Nonrepelled attacks occasionally did not result in an immediate increase in intake rate to the aggressor, nor in a decrease in intake rate to the victim (19 and 16\% of occasions, respectively). Some of these attacks could mask simple foraging interference and not foraging site displacements. For instance, parents may defend the immediate surroundings of the area where they forage to allow their offspring to forage undisturbed in a flock (Alonso \& Alonso 1993).

We conclude that foraging site displacement in common cranes is a relatively infrequent behaviour, probably because the net benefit of this site displacement strategy is not high compared with the usual foraging method of digging up cereal seeds. Strict kleptoparasitism seems a nonviable strategy, but apparently all cranes resort to displacing others from good feeding sites when they fail temporarily to obtain enough food by themselves and risk starvation. Thus it can be interpreted as a safety strategy that is always available when foraging gregariously.

\section{Acknowledgments}

We thank Anders Berglund, Ken Norris and an anonymous referee for their helpful comments and suggestions which significantly improved the manuscript. This is a contribution to project PB91-0081 of the Dirección General de Investigación Científica y Técnica.

\section{References}

Alonso, J. A. \& Alonso, J. C. 1993. Age-related differences in time budgets and parental care in wintering common cranes. Auk, 110, 78-88.

Alonso, J. A., Alonso, J. C. \& Veiga, J. P. 1984. Winter feeding ecology of the crane in cereal farmland at Gallocanta. Wildfowl, 35, 119-131.

Alonso, J. C. \& Alonso, J. A. 1992. Daily activity and intake rate patterns of wintering common cranes Grus grus. Ardea, 80, 343-351.

Alonso, J. C. \& Alonso, J. A. 1996. Updated estimate of numbers and distribution of common cranes wintering in Spain. Vogelwelt, 117, 149-152.

Alonso, J. C., Alonso, J. A. \& Bautista, L. M. 1994. Carrying capacity of staging areas and facultative migration extension in common cranes. Journal of Applied Ecology, 31, 212-222.

Alonso, J. C., Alonso, J. A., Bautista, L. M. \& Muñoz-Pulido, R. 1995. Patch use in cranes: a field test of optimal foraging predictions. Animal Behaviour, 49, 1367-1379.

Alonso, J. C., Bautista, L. M. \& Alonso, J. A. 1997. Dominance and the dynamics of phenotype-limited distribution in common cranes. Behavioral Ecology and Sociobiology, 40, 401-408.

Amat, J. A. 1990. Food usurpation by waterfowl and waders. Wildfowl, 41, 107-116.
Amat, J. A. \& Obeso, J. R. 1991. Black coots (Fulica atra; Aves, Rallidae) supplanting conspecifics from foraging sites. Ethology, 87, 1-8.

Barnard, C. J. 1984. The evolution of food-scrounging strategies within and between species. In: Strategies of Exploitation and Parasitism: Producers and Scroungers (Ed. by C. J. Barnard), pp. 95-126. London: Chapman \& Hall.

Barnard, C. J. \& Sibly, R. M. 1981. Producers and scroungers: a general model and its application to captive flocks of house sparrows. Animal Behaviour, 29, 543-550.

Bautista, L. M., Alonso, J. C. \& Alonso, J. A. 1992. A 20-year study of wintering common cranes fluctuations using time series analysis. Journal of Wildlife Management, 56, 563-572.

Bautista, L. M., Alonso, J. C. \& Alonso, J. A. 1995. A field test of ideal free distribution in flock-feeding common cranes. Journal of Animal Ecology, 64, 747-757.

Birt, V. L. \& Cairns, D. K. 1987. Kleptoparasitic interactions of Arctic skuas Stercorarius parasiticus and black guillemots Cepphus grylle in north-eastern Hudson Bay, Canada. Ibis, 129, 190-196.

Bishop, M. A. 1991. Capturing cranes with alpha-chloralose. In: Proceedings 1987 International Crane Workshop (Ed. by J. Harris), pp. 247-253. Wisconsin: International Crane Foundation.

Brockmann, H. J. \& Barnard, C. J. 1979. Kleptoparasitism in birds. Animal Behaviour, 27, 487-514.

Burger, J. \& Gochfeld, M. 1981. Age-related differences in piracy behaviour of four species of gulls, Larus. Behaviour, 77, 242-267.

Caldwell, G. S. 1980. Underlying benefits of foraging aggression in egrets. Ecology, 61, 997-998.

Caraco, T., Barkan, C., Beacham, J. L., Brisbin, L., Lima, S., Mohan, A., Newman, J. A., Webb, W. \& Withiam, M. L. 1989. Dominance and social foraging: a laboratory study. Animal Behaviour, 38, 41-58.

Charnov, E. L. 1976. Optimal foraging: the marginal value theorem. Theoretical Population Biology, 9, 129-136.

Cristol, D. A. 1992. Food deprivation influences dominance status in dark-eyed juncos, Junco hyemalis. Animal Behaviour, 43, 117-124.

Dunbrack, R. L. 1979. A re-examination of robbing behavior in foraging egrets. Ecology, 60, 644-645.

Enquist, M. \& Leimar, O. 1987. Evolution of fighting behaviour: the effect of variation in resource value. Journal of Theoretical Biology, 127, 187-205.

Ens, B. J. \& Goss-Custard, J. D. 1984. Interference among oystercatchers, Haematopus ostralegus, feeding on mussels, Mytilus edulis, on the Exe estuary. Journal of Animal Ecology, 53, 217-231.

Ens, B. J., Esselink, P. \& Zwarts, L. 1990. Kleptoparasitism as a problem of prey choice: a study on mudflat-feeding curlews, Numenius arquata. Animal Behaviour, 39, 219-230.

Furness, R. W. 1987. Kleptoparasitism in seabirds. In: Seabirds: Feeding Ecology and Role in Marine Ecosystems (Ed. by J. P. Croxall), pp. 77-84. Cambridge: Cambridge University Press.

Gochfeld, M. \& Burger, J. 1981. Age-related differences in piracy of frigatebirds from laughing gulls. Condor, 83, 79-82.

Goss-Custard, J. D. 1970. Feeding dispersion in some overwintering wading birds. In: Social Behaviour in Birds and Mammals (Ed. by J. H. Crook), pp. 3-35. London: Academic Press.

Goss-Custard, J. D., Durell, S. E. A. le V. dit \& Ens, B. J. 1982. Individual differences in aggressiveness and food stealing among wintering oystercatchers, Haematopus ostralegus L. Animal Behaviour, 30, 917-928.

Goss-Custard, J. D., Clarke, R. T. \& Durell, S. E. A. le V. dit 1984. Rates of food intake and aggression of oystercatchers Haematopus ostralegus on the most and the least preferred mussel Mytilus edulis beds of the Exe estuary. Journal of Animal Ecology, 53, 233-245.

Goss-Custard, J. D., Cayford, J. T. \& Lea, S. E. G. 1998. The changing trade-off between food finding and food stealing in juvenile oystercatchers. Animal Behaviour, 55, 745-760. 
Greig, S. A., Coulson, J. C. \& Monaghan, P. 1985. Feeding strategies of male and female adult herring gulls (Larus argentatus). Behaviour, 94, 41-59.

Hockey, P. A. R. \& Steele, W. K. 1990. Intraspecific kleptoparasitism and foraging efficiency as constraints on food selection by kelp gulls Larus dominicanus. In: Behavioural Mechanisms of Food Selection (Ed. by R. N. Hughes), pp. 679-706. London: Springer-Verlag.

Huntingford, F. A. \& Turner, A. K. 1987. Animal Conflict. London: Chapman \& Hall.

Kushlan, J. A. 1978. Nonrigorous foraging by robbing egrets. Ecology, 59, 649-653.

Kushlan, J. A. 1979. Short-term energy maximization of egret foraging. Ecology, 60, 645-646.

LeBaron, G. S. \& Heppner, F. H. 1985. Food theft in the presence of abundant food in herring gulls. Condor, 87, 430-431.

Lockie, J. D. 1956. Winter fighting in feeding flocks of rooks, jackdaws and carrion crows. Bird Study, 3, 180-190.

Maynard Smith, J. 1982. Evolution and the Theory of Games. Cambridge: Cambridge University Press.

Metcalfe, N. B. 1986. Variation in winter flocking associations and dispersion patterns in the turnstone Arenaria interpres. Journal of Zoology, 209, 385-403.
Recher, H. F. \& Recher, J. A. 1969. Some aspects of the ecology of migrant shorebirds. II. Aggression. Wilson Bulletin, 81, 140-154.

Rohwer, S. \& Ewald, P. W. 1981. The cost of dominance and advantage of subordination in a badge signaling system. Evolution, 35, 441-454.

Steele, W. K. \& Hockey, P. A. R. 1995. Factors influencing rate and success of intraspecific kleptoparasitism among kelp gulls (Larus dominicanus). Auk, 112, 847-859.

Stephens, D. W. \& Krebs, J. R. 1986. Foraging Theory. Princeton, New Jersey: Princeton University Press.

Valone, T. J. 1989. Group foraging, public information and patch estimation. Oikos, 56, 357-363.

Vickery, W. L., Giraldeau, L.-A., Templeton, J. J., Kramer, D. L. \& Chapman, C. A. 1991. Producers, scroungers and group foraging. American Naturalist, 137, 847-863.

Vines, G. 1980. Spatial consequences of aggressive behaviour in flocks of oystercatchers, Haematopus ostralegus L. Animal Behaviour, 28, 1175-1183.

Wunderle, J. M. 1991. Age-specific foraging proficiency in birds. In: Current Ornithology (Ed. by D. M. Power), pp. 273-324. New York: Plenum. 